\title{
Some Studies on Poly (vinyl chloride)/Layered Silicate Nanocomposites: Electrical, Antibacterial and Oxygen Barrier Properties
}

\author{
E. M. Sadek ${ }^{1}$, S. L. Abd-El-Messieh ${ }^{2}$, A. A.Khalil ${ }^{3}$, N. A. Fatthallah ${ }^{4}$, \\ A. I. A. Eid ${ }^{5}$, K. M. El-Ashry ${ }^{6}$ and, A.M.Motawie ${ }^{1}$ \\ ${ }^{I}$ Petrochemicals Department, Egyptian Petroleum Research Institute "EPRI", Nasr City, Cairo, Egypt. \\ ${ }^{2}$ Microwave Physics and Dielectrics Department, National Research Center Dokki, Cairo, Egypt. \\ ${ }^{3}$ Chemistry Department, Faculty of Science, Benha University, Benha, Egypt. \\ ${ }^{4}$ Petroleum Biotechnology Lab, Processes Development Department, Egyptian Petroleum Research- \\ Institute "EPRI" Nasr City, Cairo, Egypt. \\ ${ }^{5}$ Composite Materials Lab., Advanced Materials Division, Central Metallurgical Research \\ and Development Institute "CMRDI", Helwan, Cairo, Egypt. \\ ${ }^{6}$ Technical Department, Giza Plastic Company, October City, Giza, Egypt.
}

\begin{abstract}
The influence of 1.31PS organoclay content relative to PGV grade on the properties of PVC compounds was analyzed. Dielectric properties (i.e. permittivity $\varepsilon^{\prime} \&$ dielectric loss $\varepsilon^{\prime \prime}$ ) of the PVC nanocomposites were investigated in the frequency range $10^{2}-10^{5} \mathrm{~Hz}$ at room temperature $\sim 25^{\circ} \mathrm{C}$. In addition to the dielectric properties the experimental data of conductivity term $\sigma$ were also detected. The initial results show that nanoparticles of 1.31PS clay can improve electrical insulation properties of PVC by lowering $\varepsilon^{\prime \prime}(a t$ $2.5 \mathrm{phr})$ and $\sigma($ at $4 \mathrm{phr})$. The nano 1.31PS shows a significant influence on the electrical resistivity of $P V C$ by enhancing it up to $1.4 \times 10^{-11}$ ohm.cm. Biodegradation percentage (BD\%) and optical density (OD) of tested samples have been screened in testes against both Gram-positive bacteria such as Micrococcus luteus RM1 and Gram-negative bacteria such as Pseudomonas aeruginosa HR1.The particle size and morphology of PVC/1.31PS was found to play a significant role in indicating the antimicrobial efficiency. The results indicate a remarkable and significant resistance of PVC/1.31PS (2.5phr) to both kinds of microorganism, as compared with PVC containing 1.31PS (10phr). The oxygen permeability was measured at $23{ }^{\circ} \mathrm{C}$ and $50 \%$ relative humidity. With increasing 1.31PS content up to $6 \mathrm{phr}$ the oxygen permeability of the PVC matrix is reduced based on the tortuous path formation.
\end{abstract}

Key words: Poly (vinyl chloride), PGV grade and 1.31PS layered silicate, electrical properties, antibacterial activity, oxygen barrier properties.

\section{Introduction}

Organo modified clays have been widely studied in an attempt to produce exfoliated clay based polymer nanocomposites in almost every class of polymer. These nanocomposites have attracted attention because in several cases, when compared with conventional microcomposites, they have shown to give rise to more efficient mechanical reinforcement, better retention of processability, and enhanced thermal and electrical properties $[1,2]$.

Over the past few years, there have been few numbers of researches on the effect of fillers on dielectric properties of polymers [3-5].The nanotechnology applied to dielectric has certainly become an interesting topic, because the large advantage of this type of structures by the improvement in electrical characteristics were suggested [6].The addition of nanofillers into polymer matrix brings about not only the distribution of electrical field inside the materials, but also new structural behavior due to the interface interaction [7]. The nature of filler plays an important role in the polymer material stability for power cables, transformers, insulators because they are subjected to permanent multi stress action [8].

PVC is one of the electrical insulators; electrical properties of PVC are of great interest because of their wide electrical application [9]. PVC is used for manufacturing low tension-range cables [10] and of electronic devices [11]. The modifications induced by energy transfer on to PVC involves dehydrochlorination [12], the formation of radicals that generate polarizable units by oxidation[13] as chemical processes and the increase in the polarizability of degraded samples [14]. The effects of high energy exposure on PVC have been reported [15].

PVC is also widely used as biomaterials, it represents $25 \%$ of the plastics used in medical applications [16].Microporous materials as clay minerals have many applications in the industrial sector [17].Pharmacology studies have revealed that montmorillonite can adsorb bacteria such as E. coli, S. aureus and have the ability to 
immobilize cell toxins. Some researchers found that natural clay minerals showed no antibacterial effect, but could adsorb and kill bacteria when materials (i.e. organic modifiers) with antimicrobial activity were intercalated [18-20]. The important feature of this organic modifier is the presence of long hydrophobic chains in organic cations [21, 22]. Such substances are highly effective against a broad spectrum of microorganisms and widely used as antimicrobial agent [23]. However, there are very few reports in the open literatures concerning the antimicrobial activity of clays loaded with organic biocides [24, 25].

The nanocomposites offer some improvements not only in mechanical, thermal and electrical characteristics but also in other, more specific properties, such as barrier or optical properties [26]. In studies by Stoeffler et al [27] and Wan et al [28], PVC/MMT nanocomposites showed excellent barrier properties, a result which was confirmed by gas permeability measurements. Francis and Schmidt [29] found that the addition of only $2 \mathrm{wt} \%$ of OMMT resulted in a decrease of oxygen permeability in PVC/OMMT nanocomposites.

We have reported the synthesis characterization of PVC/layered silicate in our earlier studies [30].In this paper, the effect of organoclay type and content on dielectric properties, electrical conductivity and antibacterial activity as well as oxygen permeability of the plasticized PVC/clay nanocomposites was investigated.

\subsection{Materials}

\section{Experimental}

Suspension poly (vinyl chloride) (K-value 70, brand SH 1300) was purchased from Shintech-(USA). Two different types of nanoclay were used: natural bentonite hydrophilic type labeled PGV, without chemical treatment and organoclay donated 1.31 PS modified with a mixture of 15-35 wt \% octadecyl amine and 0.5-5 wt \% aminopropyltriethoxysilane. The nanoclys were supplied from Sigma Aldrich (USA), with product numbers 682659 and 682624 and initial gallery heights, $1.41 \mathrm{~nm}$, and $2.19 \mathrm{~nm}$, respectively. Dioctyl phthalate (DOP), epoxidized soybean oil (ESBO) and $\mathrm{Ba} / \mathrm{Cd} / \mathrm{Zn}$ were used as plasticizer, co-stabilizer and heat stabilizer, respectively. All the PVC ingredients were of commercial grades purchased from, Oltchem-(Romania), Skybright-(China) and Patchem-(UAE). The microorganisms selected in this study were Gram-positive Micrococcus luteus RM1 and Gram -negative Pseudomonas aeruginosa HR1, both bacterial strains were isolated from different oil polluted environments which was obtained from Petroleum Biotechnology Lab, Processes Development Department, Egyptian Petroleum Research Institute.

\subsection{PVC melt compounding}

The formulations of PVC compounds are presented in Table 1.

Table 1: Formulations of PVC Compounds

\begin{tabular}{|c|c|c|c|c|c|c|c|c|c|c|c|c|c|c|c|}
\hline \multicolumn{16}{|c|}{ Compound numbers } \\
\hline & N1 & N2 & $\mathrm{N} 3$ & N4 & N5 & N6 & N7 & N8 & N9 & N10 & N11 & N12 & N13 & N14 & N15 \\
\hline Ingredients & \multicolumn{15}{|c|}{ Contents $(\mathrm{phr})^{\mathrm{a}}$} \\
\hline PVC & 100 & 100 & 100 & 100 & 100 & 100 & 100 & 100 & 100 & 100 & 100 & 100 & 100 & 100 & 100 \\
\hline DOP & 40 & 40 & 40 & 40 & 40 & 40 & 40 & 40 & 40 & 40 & 40 & 40 & 40 & 40 & 40 \\
\hline $\mathrm{Ba} / \mathrm{Cd} / \mathrm{Zn}$ & 5 & 5 & 5 & 5 & 5 & 5 & 5 & 5 & 5 & 5 & 5 & 5 & 5 & 5 & 5 \\
\hline $\mathrm{ESBO}^{\mathrm{b}}$ & 5 & 5 & 5 & 5 & 5 & 5 & 5 & 5 & 5 & 5 & 5 & 5 & 5 & 5 & 5 \\
\hline $\mathrm{PGV}^{\mathrm{c}}$ & 0 & 0.5 & 1.5 & 2.5 & 4 & 6 & 8 & 10 & 0 & 0 & 0 & 0 & 0 & 0 & 0 \\
\hline $1.31 \mathrm{PS}^{\mathrm{d}}$ & 0 & 0 & 0 & 0 & 0 & 0 & 0 & 0 & 0.5 & 1.5 & 2.5 & 4 & 6 & 8 & 10 \\
\hline
\end{tabular}

${ }^{a}$ Part per hundred part of PVC resin., ${ }^{b}$ Epoxidized soya bean oil., ${ }^{\circ}$ Hydrophilic bentonite -nanoclay., and

${ }^{\mathrm{d}}$ Organobentonite modified with octadecylamine $15-35 \mathrm{wt} \%$ and aminopropyltriethoxysilane $0.5-5 \mathrm{wt} \%$.

The synthesis, as well as morphology, physicomechanical properties, and thermal properties of PVC nanocomposites have been reported in our earlier studies [30].

\subsection{Instrumentation}

\subsubsection{Electrical analyses}

Permittivity (dielectric constant) $\varepsilon^{\prime}$ and dielectric loss (dissipation factor) $\varepsilon^{\prime \prime}$ were carried out in the frequency range $100 \mathrm{~Hz}$ up to $100 \mathrm{kHz}$ by using an (LCR meter;Product name: AG-411 B; manufactured by Ando electric Ltd. (Japan)). The capacitance $\mathrm{C}$, the loss tangent $\tan \delta$ and the resistance $\mathrm{R}$ were obtained directly from the bridge from which $\varepsilon^{\prime}, \varepsilon^{\prime \prime}$ and conductivity $\sigma$ were calculated. The samples were molded in the form of discs with $5 \mathrm{~cm}$ diameter and $3 \mathrm{~mm}$ thickness. A guard ring (capacitor;product name: NFM/5T; manufactured by Wiss. Tech. Werkstatten GmbH, (Germany)) was used as a measuring cell. The cell was calibrated with standard materials [31] and the experimental errors in $\varepsilon^{\prime}$ and $\varepsilon^{\prime \prime}$ were found to be \pm 3 and $\pm 5 \%$, respectively. 


\subsubsection{Morphology analysis}

Phase morphologies were studied using a scanning electron microscope (SEM; product name: JSMT20; manufactured by Jeol (Japan)). For scanning electron observation the surface of the sample was mounted on a standard specimen stub. A thin coating of gold was deposited into the sample surface.

\subsubsection{Antibacterial analyses}

Biodegradation percentage (BD \%) of the tested samples was carried out in $100 \mathrm{ml}$ batch flasks containing $30 \mathrm{ml}$ basal salts medium with initial $\mathrm{pH} 7$ prepared according to[32]. Gram-positive bacteria such as Micrococcus luteus RM1 and Gram- negative bacteria such as Pseudomonas aeruginosa HR1 were incubated at $30^{\circ} \mathrm{C}$ for 21 days in a shaking incubator at $150 \mathrm{rpm}$. Finally, the samples were taken from the medium, washed with distilled water and dried overnight at $25^{\circ} \mathrm{C}$. The biodegradable percentage (BD \%) was calculated by the weight loss from the following equation $[33,34]$.

$$
\mathrm{BD} \%=\left[\left(\mathrm{W}_{\mathrm{c}}-\mathrm{W}_{\mathrm{s}}\right) / \mathrm{W}_{\mathrm{c}}\right] 100
$$

Where, $W_{c}$ and $W_{s}$ are the weight loss of control and sample sheets in grams. Each value was the average of triplicates. The optical densities (OD) of microbial suspensions were measured using a (spectrophotometer; product name: V570; manufactured by JASCO (USA)) with wave length equal to 600nm. The OD was calculated as the ratio of I/Io where I is the final light intensity at growth of bacteria at 21 days to the initial one at bacterial injection.

\subsubsection{Permeability analysis}

The oxygen transmission rate (OTR) was detected at $23{ }^{\circ} \mathrm{C}$ and $50 \%$ relative humidity according to ASTM D 1434-82, using differential pressure method as per manometric principle. The device used was a (OTR; product name: GDP-C-Gas Permeability Tester; manufacture by Brugger Feinmechanik GmbH, Munich, Bayern-80335(Germany)). The test samples with area $9852 \mathrm{~mm}^{2}$ and thickness $1.5 \mathrm{~mm}$ were prepared by compression molding and put between the top and bottom part of the permeation cell.

\section{Results and Discussions}

\subsection{Electrical analyses}

Fig. 1 shows the permittivity $\varepsilon^{\prime}$ and dielectric loss $\varepsilon^{\prime \prime}$ versus the applied frequency $f$ at temperature $25{ }^{\circ} \mathrm{C}$ for the unfilled PVC and PVC loaded with different contents of clay: (a) PVC/PGV and (b) PVC/1.31PS nanocomposites. It is clear that the permittivity $\varepsilon^{\prime}$ decreases with increasing frequency and the decrease in $\varepsilon^{\prime}$ is very prominent at low frequencies. The decrease of $\varepsilon^{\prime}$ with increasing frequency is the expected behavior in most dielectric materials. This is due to dielectric relaxation which is the cause of anomalous dispersion. From a structural point of view, the dielectric relaxation involves the orientation polarization which in turn depends upon the molecular arrangement of dielectric to be material. So, at higher frequencies, the rotational motion of the polar molecules of dielectric is not sufficiently rapid for the attainment of equilibrium with the field, hence dielectric constant seems to be decreasing with increasing frequency [35].

It is also evident that permittivity $\varepsilon^{\prime}$ increases considerably with the addition of filler as compared with unfilled PVC. This may be due to the presence of polar group in the filler. Also it was found that this increase depends on filler treatment. For PGV without treatment Fig. la $\varepsilon^{\prime}$ increases considerably with addition of PGV until certain concentration (i.e. $6 \mathrm{phr}$ ) after which a stability of $\varepsilon^{\prime}$ was noticed. On the other hand, for 1.31PS treated clay Fig. $1 \mathrm{~b}$ an increase of $\varepsilon^{\prime}$ values is observed at $2.5 \mathrm{phr}$. This attributed to the fine dispersion of 1.31PS in small clay content as corroborated by results deduced from TEM photographs previously interpreted in Ref. [30]. Beyond 2.5phr a pronounced decrease in $\varepsilon^{\prime}$ was noticed. As the filler loading increases, the density of the system is also increased and the extent of orientation of dipoles is retarded; thus, the $\varepsilon^{\prime}$ shows either decrease or stability.

It is apparent from Fig.1, which represent the variation of $\varepsilon^{\prime \prime}$ with frequency at room temperature, that the values of $\varepsilon^{\prime \prime}$ is increased at higher frequency by increasing untreated PGV filler content, Fig. 1a. This was due to the fact that filler-filler interaction was stronger than filler-polymer interaction which leads to the aggregation of filler inside the matrix. This assumption was justified by using scanning electron microscopy as will be seen later. While for 1.31PS treated filler, $\varepsilon^{\prime \prime}$ values decrease by increasing filler content up to $2.5 \mathrm{phr}$ after which no significant change in $\varepsilon^{\prime \prime}$ was noticed. This is due to the fine distribution of 1.31PS inside the PVC matrix and consequently the dipoles canceled themselves to get minimum dipole moment which is responsible for the decrease in $\varepsilon^{\prime \prime}$ values. In order to understand the variation of both $\varepsilon^{\prime}$ and $\varepsilon^{\prime \prime}$ with filler content and type, both values are illustrated graphically versus filler content at fixed frequency of $100 \mathrm{~Hz}$ as shown in Fig.2. From this Fig. it is interesting to conclude that the optimum sample recommended for insulating purposes is 

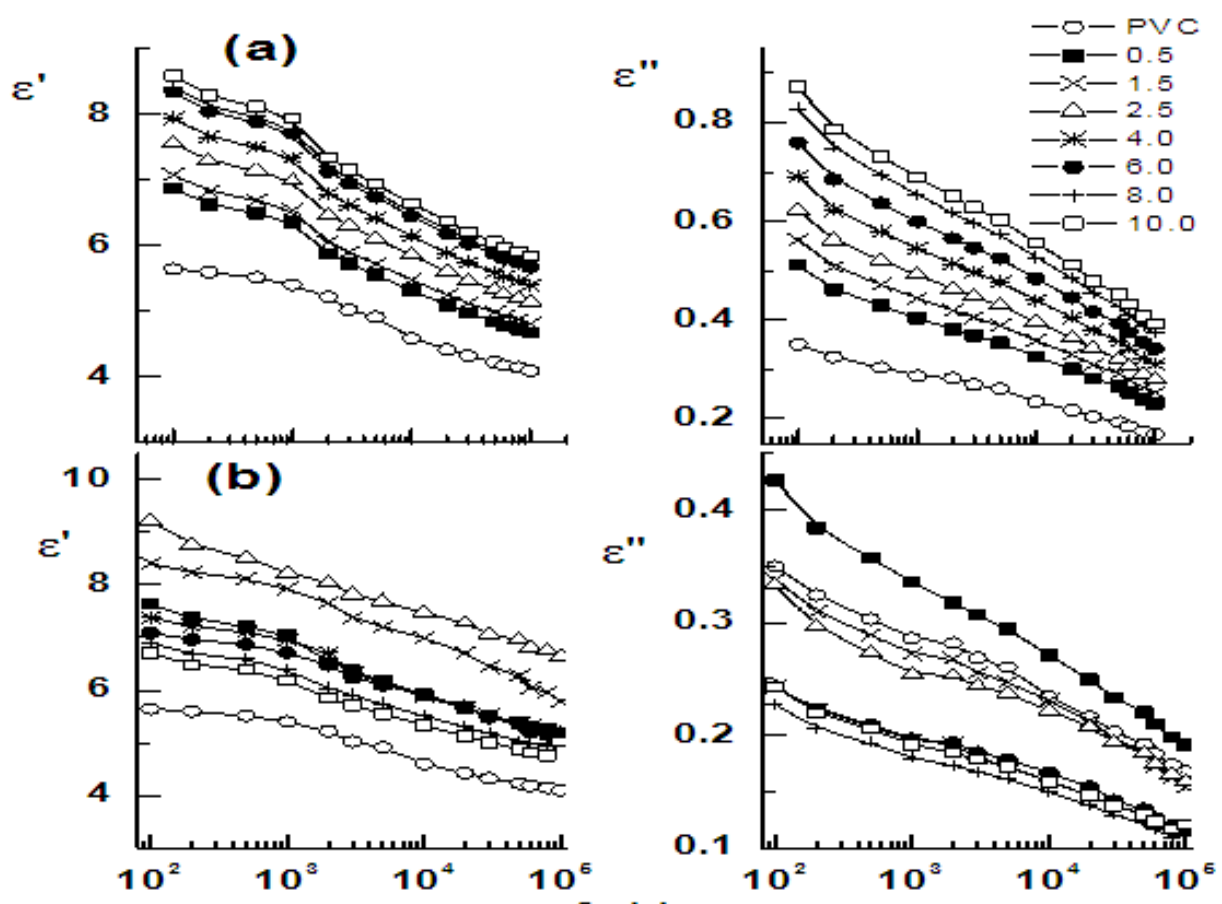

Fig.1:The Permittivity $\varepsilon^{\prime}$ and dielectric loss $\varepsilon^{\prime \prime}$ versus the applied frequency $\mathrm{f}$ for the unfilled PVC and PVC loaded with different contents of clay, a) PVC/PGV composites, b) PVC/1.31PS nanocomposites

the PVC loaded with 1.31PS treated clay at $2.5 \mathrm{phr}$ as it possess the highest $\varepsilon^{\prime}$ and lowest $\varepsilon^{\prime \prime}$ values in comparison with the other composites under investigations.

From Fig. 1, it is clear that the curves relating $\varepsilon$ "and $\log$ f are broader than Debye curve [36] indicating that more than one relaxation process is present. These processes could be attributed to mechanisms related to the main chain and its related motions [37].

In addition to the conductivity term, the analysis of the absorption curves relating $\varepsilon^{\prime \prime}$ and the applied frequency, after subtracting the conductivity term was done in terms of superposition of Fröhlich and a Havriliak-Negami functions according to the equations given elsewhere [36].

The first absorption region at the lower frequency range and fitted by Fröhlich function with relaxation time $\tau_{1}$ may be attributed to Maxwell Wagner effect. This region is found to be unaffected by the filler content with $\tau_{1}$ value about 3.4-3.6 $\times 10^{-4} \mathrm{~s}$ as shown in Fig. 3a, b. The second absorption region at the higher frequency range with relaxation time $\tau_{2}$ is found to be in the order of $10^{-5} \mathrm{~s}$, which is fitted by Havriliak-Negami function and could be attributed to the orientation of the large aggregates caused by the movement of the main chain.

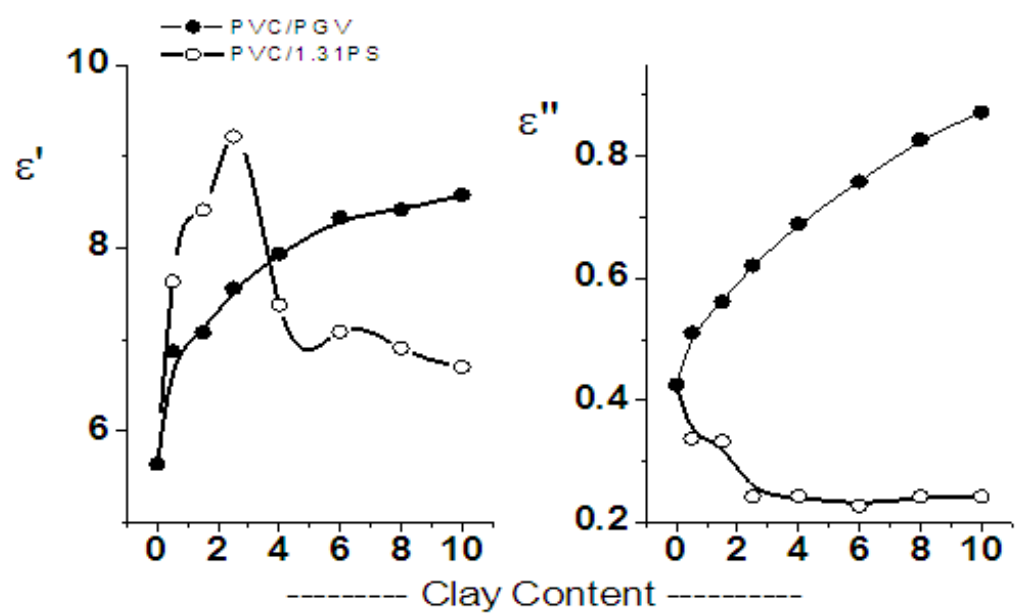

Fig.2: The permittivity $\varepsilon^{\prime}$ and dielectric loss $\varepsilon$ "at fixed frequency of $100 \mathrm{~Hz}$ versus clay content 


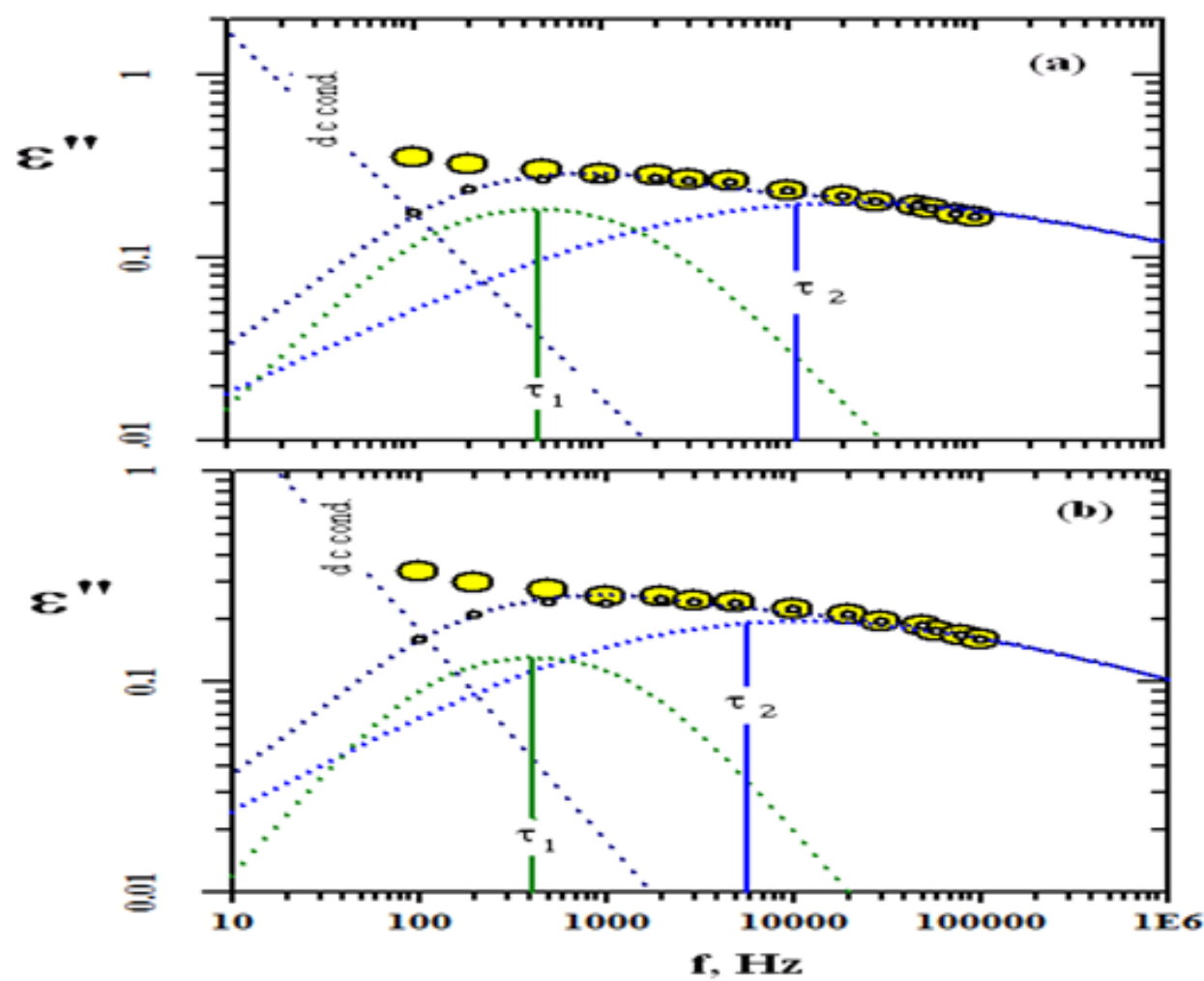

Fig.3: Example of the analyses for a) unfilled PVC, b) PVC/1.31PS (2.5phr) nanocomposite.

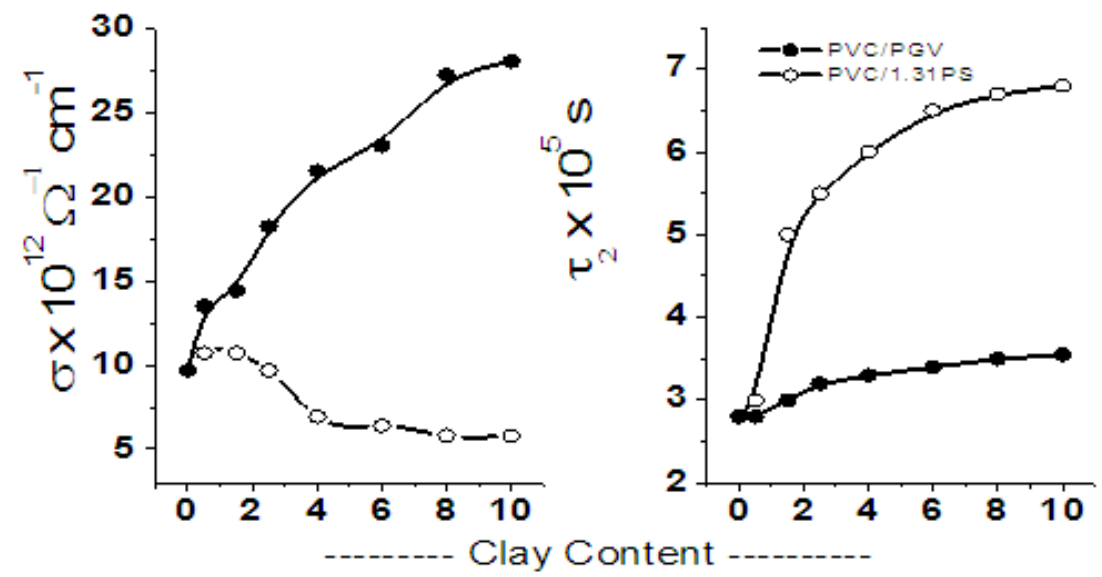

Fig.4: The second relaxation time and the electrical conductivity versus Clay content

The relaxation time associated with this region is found to increase by increasing clay content as shown in Figure 4. This increase is found to be much more pronounced in case of 1.31PS/PVC nanocomposites rather than that for PGV untreated ones. The increase in $\tau_{2}$ reflects filler-polymer interaction which increases the molar volume of the rotating units and consequently the relaxation time increases [38].

The obtained values of $\tau_{2}$ together with the electrical conductivity $\sigma$ are illustrated graphically in Fig.4. From this Fig. it is noticed that:

- The electrical conductivity $\sigma$ increases by increasing the PGV content up to 8phr after which a slight change was noticed. This is due to the aggregation of filler inside the polymeric matrix leading to the formation of a conduction path which is responsible for the increase in the electrical conductivity.

- For PVC/1.31PS nanocomposites, the electrical conductivity $\sigma$ decreases by increasing clay content up to $4 \mathrm{phr}$ after which no significant change in $\sigma$ was noticed. The decrease in $\sigma$ values is due to the fine distribution of 1.31PS which makes it easy to interact physically with PVC.

- The relaxation time $\tau_{2}$ for PVC/PGV is found to be unaffected by the filler content as its value changes from $2.8-3.6 \times 10^{-5} \mathrm{~s}$ this is due to the fact that filler-filler interaction is preferable than filler-polymer interaction so physical interaction between polymer matrix and filler is weak. 
- The second relaxation time $\tau_{2}$ for PVC/1.31PS nanocomposites is highly affected by filler percentage,$\tau_{2}$ changes from 2.8-6.8 $\times 10^{-5} \mathrm{~s}$ which reflects physical interaction between filler and polymer matrix and fine distribution of filler inside the polymer matrix. Again, this interaction increases the molar volume of the rotating unites and consequently the relaxation time increases [38].

- The obtained data for both $\sigma$ and $\tau_{2}$ justify the data previously obtained by the dielectric parameters $\varepsilon^{\prime}$ and $\varepsilon^{\prime \prime}$.

\subsection{Morphology Analysis}

The SEM photographs are shown in Fig. 5(a) PVC/PGV (8phr) and (b) PVC/1.31 PS (2.5phr). Fig.5 (b) depicts the fine dispersion of 1.31PS in PVC matrix compared with PGV filled matrix Fig.5 (a). This could be explained by the good interactions between 1.31PS (2.5phr) and PVC matrix. This means that each layer of clay has been dispersed well in the polymer matrix. On other hand, Fig. 5(a) reveals the presence of large aggregates on using PGV (8phr) that could be attributed to the poor adhesion of layered silicate to the matrix's chains leading to increased filler-filler interaction.
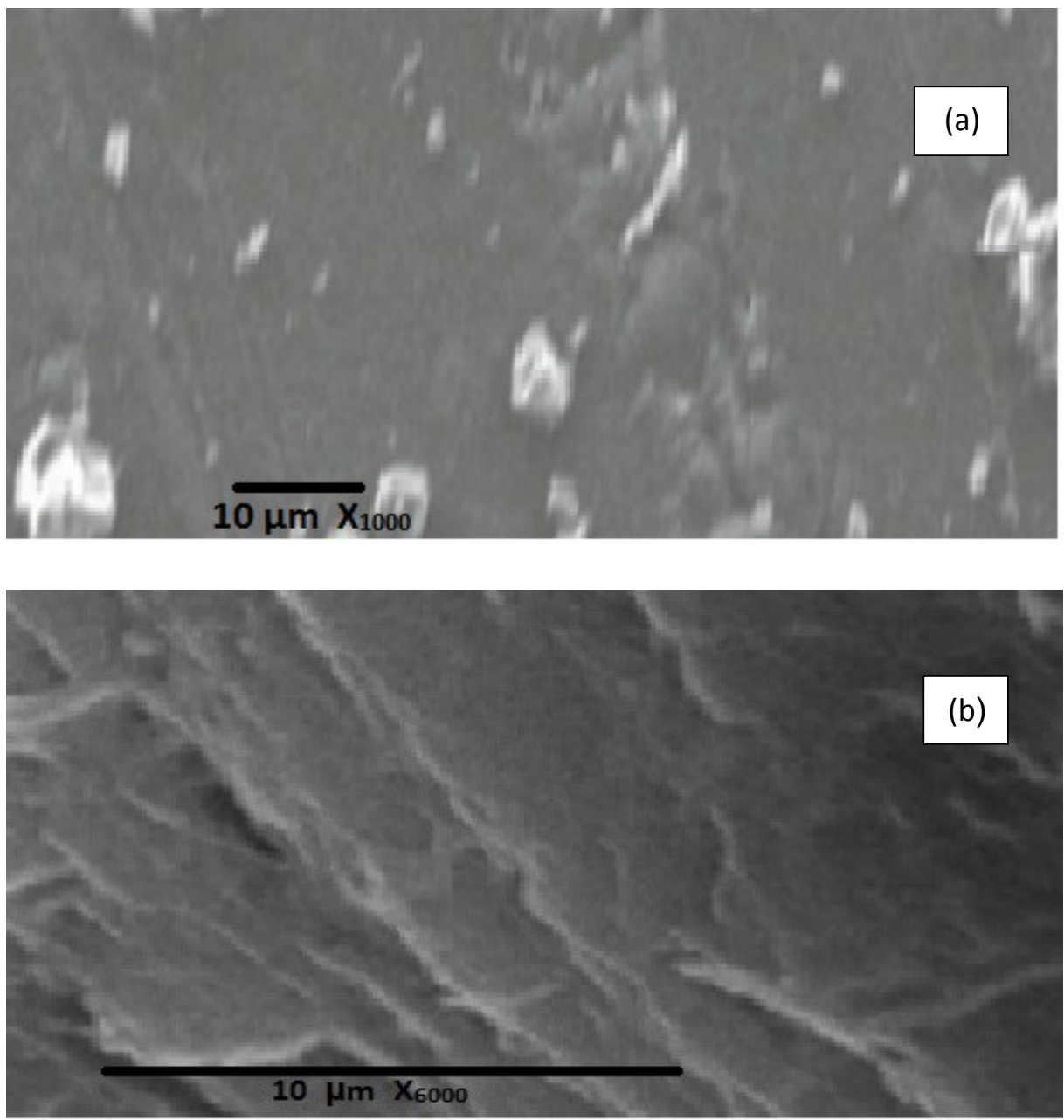

Fig.5: SEM micrograph of a) PVC/PGV (8phr), b) PVC/1.31 PS (2.5phr).

\subsection{Antibacterial Analyses}

Evaluation of antimicrobial activity of the prepared PVC/1.31PS nanocomposites has been performed, through biodegradation (BD \%) and optical density (OD) calculations, and compared with that containing hydrophilic PGV and unfilled PVC. The tested compounds have been evaluated for their activity against Grampositive bacteria (e.g. micrococcus luteus RMI) and Gram- negative bacteria (e.g. Pseudomonas aeruginosa HRI). According to the method described previously in the experimental part, results of Table 2 indicate that the unfilled PVC has 2.040 and 3.400\% biodegradation percentages (BD \%) against both Gram-positive and Gramnegative bacteria, respectively. This indicates the antibacterial activity of unfilled PVC. As expected, the 
chlorine group is the commander in the inhibition process; therefore, PVC is effective in inhibiting the growth of microorganisms [39].

For PVC nanocomposites, the data in Table 2 indicate that the variation in the antibacterial activity can be attributed to the difference in the morphology and particle sizes of 1.31PS nanocomposite which influences interaction with the bacterial cell wall. The poor ability of the bacteria to grow on the PVC/1.31PS (2.5phr), with positively charged quaternary ammonium groups as a sole source of carbon and energy, indicates its low biodegradability at this content so that it approaches that of unfilled PVC. This means that PVC/1.31PS (2.5phr) samples have higher inhibitory effect against the studied bacteria. This can be attributed to the filler exfoliation inside the matrix at $2.5 \mathrm{phr}$ as shown from XRD and TEM photograph previously explained in our study [30].Similar results were found by Ufana, et al [40]. This was in agreement with an earlier work reported by Alexandra et al [39] who found that most antimicrobial polymers are positively charged and by Kenawy et al. [41] who accepted that the mechanism of the bactericidal action of the polycationic biocides involves destructive interaction with negatively charged cell wall and/or cytoplasmic membranes. On other hand, the data in Table 2 indicate higher affinity of bacteria towards PVC/1.31PS (10phr). This was in accordance to the fact that, the 1.31PS nanoparticles were found to be agglomerated in a large particle size distribution and randomly dispersed in the PVC matrix [30]. This hampers the antibacterial activity of the composite and in turn increases the biodegradation. Similar results were found in Ref. [40]. Table 2 also indicates that the mechanism of action of the prepared samples was found to differ for Gram-positive and gram-negative bacteria, owing to the difference in the composition of the cell wall. Gram-negative bacteria have an additional membrane with a bilayer phospholipid structure, which protect the inner cytoplasmic membrane to greater degree against the adverse action of the polymeric biocides [39].

On other hand, the absence of quaternary ammonium groups in the untreated PGV clays was considered as responsible for the bacterial activity; making the PVC samples more degradable with respect to organo 1.31PS filled PVC.

The data in Table 2 indicate the lowest I/Io for PVC/1.31PS (2.5phr) as compared with other tested compounds. This means minimum turbidity after 21 days which in turn reflects bacterial inhibition after this period with lowest biodegradation percentage. Thus, the results of biodegradation percentages were inconsistent with the optical density data.

Table2: Biodegradation percentage (BD \%) and Optical Density of final O.D600 / initial O.D600 (I/Io) of unfilled PVC, PVC/PGV composites and PVC/1.31PS nanocomposites

\begin{tabular}{|c|c|c|c|c|}
\hline \multicolumn{5}{|c|}{ Gram-positive Micrococcus luteusRM1 } \\
\hline Samples & $\begin{array}{c}\text { Control } \\
\text { (A biotic) } \\
(\mathbf{W c}, \mathbf{g})\end{array}$ & $\begin{array}{r}\text { Sample } \\
\text { (Biotic) } \\
(W s, g)\end{array}$ & BD \% & $\mathbf{I} / \mathbf{I}_{\mathbf{0}}$ \\
\hline Unfilled PVC & 0.147 & 0.144 & 2.040 & 0.878 \\
\hline PVC/PGV (2.5phr) & 0.142 & 0.123 & 13.380 & 3.192 \\
\hline PVC/1.31PS (2.5phr) & 0.150 & 0.147 & 2.000 & 0.800 \\
\hline PVC/1.31PS (10phr) & 0.149 & 0.137 & 8.050 & 0.845 \\
\hline \multicolumn{5}{|c|}{ Gram -negative Pseudomonas aeruginosaHR1 } \\
\hline Unfilled PVC & 0.147 & 0.142 & 3.400 & 0.898 \\
\hline PVC/PGV (2.5phr) & 0.142 & 0.118 & 16.900 & 5.485 \\
\hline PVC/1.31PS (2.5phr) & 0.145 & 0.140 & 3.440 & 0.666 \\
\hline PVC/1.31PS (10phr) & 0.145 & 0.127 & 12.410 & 2.149 \\
\hline
\end{tabular}

\subsection{Permeability Analysis:}

Fig.6 graphically shows the oxygen transmission rate versus clay content. It can be seen that the polar character of the unfilled PVC is responsible for increasing its oxygen permeability at $50 \%$ humidity. As water molecules attach on the polar group, the polymer cohesion is weakened, thus, higher oxygen transmission occurs [42].On the contrary, the change in oxygen permeability of nanocomposites is controlled by clay content and microstructure. The clay layer themselves are impervious to oxygen providing barrier resistance [43, 44]. The presence of silicate layers are expected to cause a decrease in oxygen permeability because of more tortuous paths for the diffusing molecules that must bypass impenetrable platelets. This phenomenon is significant when the filler is of nanometer size with high aspect ratio [45]. It was deduced that with increasing clay content in a nanocomposites up to $6 \mathrm{phr}$, the permeability of oxygen was reduced. At low concentration (2.5phr), permeability decrease was not significant indicating there was insufficient platelets to provide resistance to permeability and tortuous path required. 


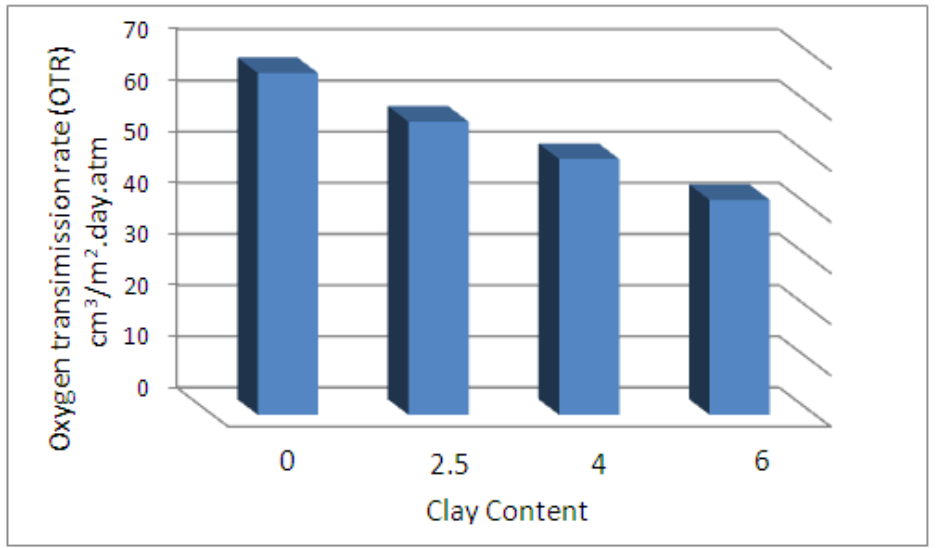

Fig.6: Oxygen permeability for the various PVC/1.31PS nanocomposites as a function of clay content.

\section{Conclusion}

On the basis of obtained data, the following conclusions can be drawn. PVC/clay nanocomposites have been prepared by melt processing with the use of commercially availableclay donated by PGV and1.31PS.Nanocomposites with the platelets of modified clay 1.31PS dispersed in PVC matrix exhibited insulating properties as it has the highest $\varepsilon^{\prime}$ and lowest $\varepsilon^{\prime \prime}$ with increasing in $\tau_{2}$ values when it compared with the other composites under investigation. The enhanced antibacterial effect of PVC/1.31PS can be correlated to nanosize morphology. The smaller size as well as the homogenous dispersion of 1.31PS (2.5phr) nanoparticles in PVC, is presumably responsible for higher antibacterial activity in this case as compared with 1.31PS (10phr). This indicates the poor ability of the studied microbial strain to grow on the studied samples as a sole source of carbon and energy indicating lower biodegradability at $2.5 \mathrm{phr}$. Also the presence of quaternary ammonium groups in the 1.31PS clays is the factor of increased antibacterial activity in contrast to that of PGV clay. The nanocomposites maintained their good permeation behavior also at $50 \%$ humidity by creating a tortuous path that retards the oxygen permeability through PVC matrix.

\section{References}

[1]. LeBaron PC, Wang Z, and Pinnavaia TJ, 1999, Polymer-layered silicate nanocomposites: an overview. Appl. Clay Sci, 15: 11-29.

[2]. Dimitry OIH, Saad ALG, 2007, ICCM-16-16 ${ }^{\text {th }}$ International conference on composites materials, Kyoto, Japan, pp.1-10.

[3]. Simeõs AZ, and Riccardi CS, 2009, Dielectric spectroscopy analyses of $\mathrm{SrBi}_{4} \mathrm{Ti}_{4} \mathrm{O}_{15}$ films obtained from soft chemical solution.Adv. Mater. Sci. Eng.Article ID928545; 6 pages.

[4]. Lai CY, Sapuan SM, Ahmad M, Yahya N, and Dahlan KZ HM, 2005, Mechanical and electrical properties of coconut coir fiberreinforced polypropylene composites. Polym. Plast. Technol. Eng, 44: 619-632.

[5]. Imai T, Sawa F, Yoshimitsu T, Ozaki T, and Shimizu T, 2004, CEIDP '04 Conference on Electrical Insulation and Dielectric Phenomena, Boulder, Colorado; United States, pp 402-405.

[6]. Tanaka T, Montanari GC, and Mülhaupt R, 2004, Polymer nanocomposites as dielectrics and electrical insulation-perspective for processing technologies, material characterization and future applications. IEEE Trans. Dielectr. Electr. Insul, 11: 763-784.

[7]. Lewis TJ, 2004, Interfaces are the dominant feature of dielectrics at the nanometric level. IEEE Trans. Dielectr. Electr. Insul; 11:739-753.

[8]. Tanaka T, 2002, Ageing of polymeric and composite insulating materials. Aspects of interfacial performance in ageing. IEEE Trans. Dielectr. Electr. Insul, 9:703- 716.

[9]. Yassin AA, and Sabaa MW, 1990, Degradation and stabilization of poly (vinyl chloride). J. Macromol. Sci., Rev. Macromol. Chem. Phys, C30 (3-4): 491-558.

[10]. Nedjar M, Beroual A, and Boubalkeur A, 2006, Influence of thermal ageing on the electrical of poly (vinyl chloride). J. Appl. Polym. Sci, 102:4728-4733.

[11]. Ekelund M, Edin H, and Gedde UW, 2007, Long-term performance of poly (vinyl chloride) cables. Part 1: mechanical and electrical performances. Polym. Degrad. Stab, 92: 617-629.

[12]. Zaharescu T, Nemes E, Tomescu A, and Grosu E, 2006, Radiation modifications of functional properties in PVC/mica electrical insulations. Polym. Bull, 57:83-90.

[13]. Colombani J, Raffi J, Gilardi T, Troulay M, Catoire B, and Kister J,2006, ESR studies on poly (vinyl chloride) irradiated at medium and high doses. Polym. Degrad. Stab, 91:1619-1628.

[14]. Esposti GD, Delbo L, Faucitano R, and Albini A, 1999, Characterization of the ageing process of gamma-irradiated PVC samples using TSDC measurements. Radiat. Phys. Chem, 54: 203-205.

[15]. Zaharescu T, Jipa S, Popescu ED, Kappel W, and Samoilescu G, 2008, Electrical properties of PVC/mica insulations. Mater. Plast, 45: 154-157.

[16]. Tickner JA, Schettler T, Guidotti T, McCally M, and Rossi M, 2001, Health risksposed by use of Di-2-ethylhexyl phthalate (DEHP) in PVC medical devices: A critical review. Am. J. Ind. Med 39:100-111.

[17]. Bandosz TJ, Jagiello J, Amankwah KAG and Schwarz JA, 1992, Chemical and structural properties of clay minerals modified by inorganic and organic material clays. Clay Miner, 27: 435-444.

[18]. Herrara P,Burghardt RC, Phillips TD,2000, Adsorption of Salmonella enteritidis by cetylpyridinium-exchanged montmorillonite clays. Vet. Microbial, 74:259-272.

[19]. Zhou YH, Xia MS, Ye Y, Hu CH, 2004, Antimicrobial ability of $\mathrm{Cu}^{2+}$-montmorillonite. Appl. Clay Sci, 27: $215-218$. 
[20]. $\mathrm{Hu} \mathrm{CH}$, and Xia MS, 2006, Adsorption and antibacterial effect of Copper-exchanged montmorillonite on Escherichia coli K88.Appl. Clay Sci, 31:180-184.

[21]. Fores TD, Hunter DL, Paul DR, 2004, Nylon-6 nanocomposites from alkylammonium-modified clay: the role of alkyl tails on exfoliation. Macromolecules, 37:1793-1798.

[22]. Yang I-K, and Tsai P-H, 2006, Intercalation and viscoelasticity of poly (ether-block-amide) copolymer/montmorillonite nanocomposites: Effect of surfactant. Polym. J, 47: 5131-5140.

[23]. Hugo WB, Russell AD, and AyliffeGAJ, 1999, Principles and practice of disinfection preservation and sterilization.Ed. by Blackwell Science publishing.

[24]. Nigmatullin R, Gao F, and Konovalova V, 2008, Polymer-layered silicate nanocomposites in the design of antimicrobial materials. J. Mater. Sci, 43:5728-5733.

[25]. Wang X, Du Y, Yang J, Tang Y, and Luo J, 2008, Preparation, characterization and antimicrobial activity of quarternized chitosan/organic montmorillonitena nocomposites.J. Biomed. Mater. Res. Part A, 84:384-390.

[26]. Pagacz J, and Pielichowaski K, 2009, Preparation and characterization of PVC-montmorillonitena nocomposites-a review.J.Vinyl and Addit. Technol, 15: 61-76.

[27]. Stoeffler K, Lafleur PG, and Renault J, 2008, Thermal decomposition of various oniumorganoclays: effect of polyethylene terephthalate nanocomposites properties.Polym. Degrad. Stab, 93: 1332-1350.

[28]. Wan CY, Qiao XY, Zhang Y, and Zhang YX, 2003, Structures and mechanical properties of PVC/Na+- montmorillonite nanocomposites. Chin. Chem. Lett., 14: 417-418.

[29]. Francis N, and Schmidt DF, 2007, SPE ANTEC $65^{\text {th }}$ Conference proceedings. PVC/layered silicate nanocomposites. Lowell, Massachusetts, United States, pp1238-1242.

[30]. Motawie AM, Khalil AA, Eid AIA, El-Ashry KM and Sadek EM, 2014, Some studies on poly (vinyl chloride)/layered silicate nanocomposites Part 1, Morphology, physico-mechanical, and thermal properties. J. Appl. Sci. Res, 9:6355-6364.

[31]. Abd-El-Messieh SL, El-Sabbagh S, and Abadir F I, 1999, Dielectric relaxation and mechanical investigation of ethylene propylene diene monomer rubber with some crosslinking additives. J. Appl. Polym. Sci, 73: 1509-1519.

[32]. Piddington, CS, Kovacevich BR, and Rambosek J, 1995, Sequence and molecular characterization of a DNA region encoding the dibenzothiophene desulfurization operon of Rhodococcus sp. strain IGTS8. Appl. Environ. Microbiol, 61: 468-475.

[33]. Sonal GC, Sachin GC, Bhosale PR, Nakade DB, Raut PD, 2012, Studies on degradation of synthetic polymer Nylon 6 by fungus Trametesversicolor NCIM 1086.Int. J. Environ. Sci. Technol2: 2435-2442.

[34]. Moore GF, and Saunders SM,1998,Advances in biodegradable polymers, ed by Smithers Rapra Publishing.

[35]. Akram M, Javed A, Rizvi TZ, 2005, Dielectric Properties of Industrial Polymer Composite material.Tur J Phys, $29: 355$-362.

[36]. Reffaee ASA, El-Nashar DE, Abd-El-Messieh SL, and Abd-El Nour KN, 2009,Electrical and mechanical properties of acrylonitrile rubber and linear low density polyethylene composites in the vicinity of the percolation threshold. Mater. Des, 30: 3760-3769.

[37]. Ku CC, and LiepinsR, 1987, Electrical properties of polymers, chemical properties, Hanser publishing.

[38]. Mansour SH, El- Nashar DE, and Abd-El-Messieh SL, 2006, The effect of chemical treatment of wood flour on the properties of styrene butadiene rubber/ polystyrene composites. J. Appl. Polym. Sci, 102: 5861-5870.

[39]. Muñoz-Bonilla A, and Fernandez-Garcia M, 2012, Polymeric materials with antimicrobial activity. Prog.in Polym. Sci, 37:281339.

[40]. Riaz U, Khan S, Islam MN, Ahmed S, and Ashraf SM, 2008, Evaluation of antibacterial activity of nanostructured poly (1naphthylamine) and its composites. J. Biomater. Sci. Polymer Edn. 19:1535-1546.

[41]. Kenawy ER, Abdel-Hay FI, El-Shanshoury AERR., and El-Newehy MH, 2002, Biologically active polymers. V. Synthesis and antimicrobial activity of modified poly (glycidyl methacrylate-co-2-hydroxyethylmethacrylate) derivatives with quaternary ammonium and phosphonium salts. J. Polym. Sci., Part A: Polym. Chem, 40:2384-2393.

[42]. Gatos KG, and Karger-Kocsis J, 2007, Effect of the aspect ratio of silicate platelets on the mechanical and barrier properties of hydrogenated acrylonitrile butadiene rubber (HNBR)/layered silicate nanocomposites. Eur. Polym. J, 43:1097-1104.

[43]. Dritis VA, and Tchoubar C, 1990, X-ray diffraction by disordered lamellar structure, Springer publishing.

[44]. Bharadwaj RK, 2001, modeling the barrier properties of polymer-layered silicate nanocomposites. Macromolecules, 34: 9189-9192.

[45]. Pannirselvam M, Genovese A,Jollands MC, Bhattacharya SN, and Shanks RA, 2008, Oxygen barrier property of polypropylenepolyether treated clay nanocomposite. Express Polymer Letters, 2: 429-439. 